\title{
O FENÔMENO VARIÁVEL DA POSIÇÃO DOS CLÍTICOS PRONOMINAIS EM CARTAS MANUSCRITAS DOS TEMPOS ÁUREOS DA BORRACHA
}

\author{
THE VARIABLE PHENOMENON OF THE POSITION OF \\ PRONOMINAL CLYTICS IN HANDWRIT'TEN LETTERS \\ FROM THE GOLDEN AGES OF RUBBER
}

\begin{abstract}
RESUMO: Neste artigo, tratamos da constituição de um corpus diacrônico do português registrado no Amazonas do século XIX. Os dados a que fazemos referência resultam de pesquisa que tem selecionado e organizado cartas manuscritas datadas de 1877 a 1989; correspondência, fundamentalmente de tom comercial, firmada entre pessoas físicas e jurídicas e a empresa J. G. Araújo, ao longo de 112 anos. Sob o modelo sociolinguístico quantitativo laboviano (LABOV, 1972), trazemos a descrição das formas verbais em uso no conjunto de dados, com destaque para as suas realizações escritas e para a sua relação com pronomes na função objeto. Para tal, analisamos 46 cartas, exemplares do século XIX, (destas, 21 com mais de uma página), com o propósito de estudar qual é o uso majoritário no material em estudo: se a próclise, se a ênclise. Nossos resultados apontam tendência à posição pré-verbal do clítico em relação ao verbo, com $57,31 \%$ de ocorrências de 'me' e 'lhe' em relação a um total de 164 dados.

Palavras-chave: Sociolinguística; Variação sintática; Pronomes; Cartas manuscritas.
\end{abstract}

\begin{abstract}
In this article, we deal with the constitution of a diachronic corpus of Portuguese Language registered in the Amazon of the 19th century. The data to which we refer is the result of research that has selected and organized handwritten letters dated from 1877 to 1989; correspondence, mainly of a commercial tone, signed between individuals and companies and the company J. G. Araújo, over 112 years. Under the Labovian quantitative sociolinguistic model (LABOV, 1972), we describe the verbal forms in use in the data set, with emphasis on their written achievements and their relationship with pronouns in the object function. To this end, we analyzed 46 letters, copies of the 19th century, (among them, 21 with more than one page), with the purpose of studying what is the major use in the material under study: if the proclisis, if the enclisis. Our results point to a tendency towards the pre-verbal position of the clitic in relation to the verb, with $57.31 \%$ of occurrences of ' $m e$ ' and 'lhe' in relation to a total of 164 data.
\end{abstract}

Keywords: Sociolinguistics; Syntactic variation; Pronouns; Handwritten letters.

\section{Introdução}

A pesquisa que estamos desenvolvendo toma como seu objeto de estudo um conjunto de cartas manuscritas que está, desde 1989, sob a guarda do Museu Amazônico, órgão suplementar da Universidade Federal do Amazonas. As correspondências nos reportam à história da empresa

\footnotetext{
${ }^{1}$ Doutora em Letras pela Universidade Federal do Paraná; professor associado da Universidade Federal do Amazonas; tem experiência na área de Linguística, com ênfase em Sociolinguística e Dialetologia, atuando principalmente nos seguintes temas: variação e mudança linguísticas; o pronome reflexivo "se".
} 
J.G. Araújo, tida como a maior casa aviadora dos tempos áureos da borracha entre o final do século XIX e a primeira metade do século XX, conforme material da Divisão de Pesquisa e Documentação Histórica do Museu.

As cartas de que tratamos aqui são os originais das cartas manuscritas que foram dirigidas a Joaquim Gonçalves de Araújo (1860-1940), mais conhecido como Comendador J. G. Araújo, e a membros da mesma família, em decorrência de uma prática comercial da época: o sistema de aviamento, como descrito em (1) e (2) ${ }^{2}$.

(1) Queirão ter abondade mandar me no seguinte vapor as mercadorias constantes da notta abaicho

(2) Recebi os objectos que vm ${ }^{\text {ces }}$ se dignaram mandar-me no Amasonas

É assim, portanto, com o relato dos pedidos de compra, ou ainda com os casos de representação (via procuração) para a resolução de negócios e de recebimentos de valores em dinheiro, que vamos conhecendo como se escrevia no Amazonas de há mais de dois séculos. Temos notas sobre abreviaturas e expressões de fechamento de carta, como em (3) e (4); as saudações de abertura, tal como em (5) ${ }^{3}$; os casos de contração e combinação envolvendo preposições (d'ahi, d'este, d'antes e d'essa); além das muitas e variadas soluções para a grafia de formas nominais e verbais: 'trez, dezejando, pesso (ou peço), tranzação, abaicho, podião, dessedir, presado (ou prezado), promptas e effectue'.

(3) Recommende-me a todos - Sem $\mathrm{m}^{\mathrm{s}}$ outro assumpto Seo Am ${ }^{\circ}$ Velho

(4) Desejando-lhe todas as prosperid ${ }^{\text {es }}-$ sou De V.S ${ }^{a}$

(5) $\mathrm{Am}^{\circ}$ e $\mathrm{Sen}^{\mathrm{r}}$ com praser accuso arecepção de sua carta

Além, pois, do que o conjunto de dados nos propicia em termos de estudos linguísticos, nossa pesquisa de perspectiva diacrônica acaba por ensejar, no nosso caso em particular, o conhecimento sobre o quotidiano dos que viveram no Amazonas dos séculos XIX e XX. Sabemos, por exemplo, dos phosphoros, do pirarucu, da tartaruga e do bacalháo; assim citados, em carta de Tabatinga, aos 15 de janeiro de 1879.

Somos familiarizados, também, com as doenças (ou, as moléstias) enfrentadas à época, como as descritas em 23 de junho de 1881, e conhecemos, por fim, as impressões pessoais de quem aqueles difíceis tempos viveu; do que podem ser exemplo os mosquitos (ou os carapanãs) que não deixavam ninguém sossegar, conforme os registros de janeiro de 1879: "a praga é tanta que não se pode suportar por que chegão morder $\mathrm{p}^{\mathrm{r}}$ cima das meias e da roupa do corpo".

Todas as cartas a que fazemos referência neste trabalho foram escritas entre os anos de 1879 e 1889, quando ainda não tinha o Brasil uma lei para normatizar a ortografia do nosso português. É só no início do século XX que Portugal estabelece, com o Primeiro Formulário Ortográfico de 1911, um modelo de escrita correta; iniciativa que, no entanto, não foi adotada no Brasil.

No que se refere à escrita, as cartas nos remetem ou ao grego clássico ou ao latim, como (6) que traz peior, comparativo de superioridade de malus; ou (7), que demonstra como se escrevia o adjetivo ciente: com sc (sciente de), tal como scientia e scio, substantivo e verbo latinos.

(6) Emfim é o peior lugar que tinha visto ${ }^{4}$.

(7)Tenho presente o estimado favôr de vm. ${ }^{\text {cês }}$ de 28 do mês já findo sciente e agradecido

Ainda sobre a forma de escritura, temos numerosos exemplos não somente do emprego de consoantes dobradas, como em 'remettermos, sofficiente e aquella', mas também dos casos em que se repetem o c e o p, como em 'objectos, assumpto, facturas e escripto'. Também não são poucos os dados de variação e/i e o/u, como em 'chapéo, distino, principaes'.

Veja-se também o trecho de carta em (8), a seguir, datada de 9/6/1881. Trata-se, nesta última,

20 trecho de carta em (1) é de 15 de fevereiro; o que está em (3), de 29 de março. Ambos de 1881. Notemse 'abondade' sem que o artigo esteja separado do substantivo, 'abaicho' com ch e 'Amasonas', com s, por exemplo, nome de um dos muitos barcos que transportavam as cartas e as mercadorias solicitadas à capital Manaus.

3 Os trechos de carta, em (3) e (4), são de janeiro e fevereiro de 1879, respectivamente. Já o dado em (5) diz respeito a uma carta com data de 9 de abril de 1879.

4 Os dados em (6) e (7) são de junho de 1881. 
do uso do 'h', que remonta ao galego (MELO 1985, p. 40) e é produtivo em nosso conjunto de dados: 'hum, humidade, ahí'. Novamente, quando "ainda não se tinham definido normas ortográficas gerais para a escrita do português" (MATTOS E SILVA 2006, p. 57).

(8) Sentimos que tivessem ahí chegado algumas caixas em máo estado, o que pode ser devido, como v.m. ${ }^{\text {cês }}$ dizem, a terem-se encaixotado ainda frescas, ou a humidade que apanhassem até ahí.

As análises linguísticas que trazemos a este artigo dizem respeito, no entanto, a aspectos sintáticos, mais particularmente aos que podem estar relacionados aos verbos empregados nas cartas antigas: seus registros escritos e sua relação com clíticos pronominais. Perguntamo-nos sobre qual é o uso majoritário nas cartas em estudo, exemplares do século XIX: se da próclise, como em (9); se da ênclise, como em (10). A primeira carta, de 10/4/1879; a segunda, de 20/4 do mesmo ano.

(9) não lhe remeto agora dinheiro $\mathrm{p}^{\mathrm{r}}$ que $\mathrm{q}^{\mathrm{do}}$ ovapor aqui chegou ja havião recibido dinheiro no dia $1^{\mathrm{O}}$

(10) pois é para uma encommenda mas eu disse-lhe que podia custar a 1300 cada lata

Tem este nosso trabalho a urgência em primeira mão, porque muitas das cartas estão danificadas ou ilegíveis, dificultando, muitas vezes, a coleta dos dados linguísticos. É também por isso que corremos em favor de sua digitalização.

\section{Fundamentação teórica}

Este trabalho é um recorte do projeto de pesquisa "Cartas dos séculos XIX e XX: organização de um corpus diacrônico do português registrado no Amazonas no período áureo da borracha", cujo maior objetivo é conhecer as características do português empregado em cartas manuscritas dos séculos em estudo, a partir da seleção e organização de um conjunto de dados escritos, nos quais espera-se encontrar elementos linguísticos de natureza diversa, que possivelmente evidenciem supostas características de uma variedade típica do português registrado no Amazonas.

Metodologicamente, o tratamento adotado segue o modelo sociolinguístico quantitativo laboviano; modelo que defende, como princípio, a ideia de que toda língua é, por definição, diversificada (LABOV, 1972). Tal diversidade se explica pela convivência, num determinado estágio da língua, de mudanças acontecidas ao longo do tempo, isto é, a diversidade sincrônica se explica pelas mudanças ocorridas diacronicamente.

O sistema linguístico, do ponto de vista sincrônico, é considerado num determinado momento histórico. Cada fato linguístico, quando analisado sincronicamente, é observado quanto ao seu funcionamento, ou seja, a descrição linguística se dá pela observação da "relação entre coisas coexistentes" (PETTER 2011, p. 18). Quer dizer, na sincronia, a pergunta gira em torno de como funcionam os fatos linguísticos num determinado momento. Na diacronia, por sua vez, são estudadas as transformações vividas pelos fatos linguísticos, o que permite que se estabeleçam comparações entre os fatos em estudo e aqueles que os precederam ou sucederam. Na primeira, como os fatos linguísticos estão se comportando num estado da língua; na segunda, como os fatos linguísticos se comportam em sucessivos estados de língua.

No método laboviano, então, de pesquisa alicerçada em dados concretos de fala ${ }^{5}$, ganham grande importância os fatores sociais, tais como a idade, o sexo, a escolaridade, dos pesquisados. Sob tal perspectiva de estudo de uma língua, dá-se a investigação dos aspectos linguísticos correlacionados aos sociais, com vistas à descrição dos empregos linguísticos concretos, em especial os de caráter heterogêneo (MOLLICA 2003, p.9).

O caráter heterogêneo do sistema linguístico é resultado, por sua vez, da identificação de formas que se comportam como variantes, que "são alternativas de se dizer a mesma coisa, ou seja,

5 Os dados, de escrita, com que trabalhamos refletem o que Silva (2006, p.17) registra sobre pesquisa com dados escritos do português arcaico. Discussão que retomamos adiante. 
oferecem a mesma informação referencial" (COELHO et al. 2010, p. 47).

O termo variantes ajuda a compor o princípio da variação linguística, especialmente considerado pela Sociolinguística Variacionista (WEINREICH et al. 2006 [1968]), ciência segundo a qual o pressuposto básico do estudo da variação no uso da língua é o de que a "heterogeneidade linguística, tal como a homogeneidade, não é aleatória, mas regulada, governada por um conjunto de regras" (NARO 2003, p. 15). Quer dizer, dado o pressuposto básico, identificam-se quais formas são preferidas e por quê, se por razões internas ou externas ao sistema linguístico.

Para a descrição, portanto, do comportamento sintático envolvendo verbos e clíticos pronominais e com vistas ao encontro das variáveis linguísticas que possam estar motivando ou restringindo a variação em questão, definimos a variável dependente de nossa pesquisa: posição pré/pós verbal do clítico em relação ao verbo, como demonstrado em (11) e (12), a seguir:

(11) Este papel que [trecho danificado] $\underline{V}$. me vendeo $p^{r} m^{\text {to }}$ vem de beira dourada

(12) $\mathrm{p}^{\mathrm{r}}$ isso me mande as que pesso na carta de seo irmão, tendo em vista o preço, $\mathrm{p}^{\mathrm{r}}$ que as que trouxe $\mathrm{q}^{\mathrm{do}}$ vim de ahi erão finas e $\underline{\mathrm{V}}$. empurrou me $\mathrm{p}^{\mathrm{r}} 800 \mathrm{r}^{\mathrm{s}}$

Em (11), lemos trecho de carta de 10 de fevereiro de 1879. Ali, temos o uso proclítico de 'me' em relação ao verbo 'vendeo'. Em (12), a carta é de 1879, sem mês e ano conhecidos. Traz 'me' em posição enclítica em relação a 'empurrou'. Fazemos notar, também, que os dois verbos em questão traduzem ações passadas e completadas no próprio passado e que, em ambos os casos, 'me' é antecedido de uma das correntes abreviaturas para vossa mercê - um V. em maiúsculo: no primeiro dado, 'V. me vendeo' e, no outro, 'V. empurrou me'.

Breves palavras sobre V. Entendemos tal uso (de V, seguido de ponto e em maiúsculo) como uma das abreviaturas usadas nas cartas manuscritas para Vossa Mercê. Temos visto com este fim, para o plural e para o singular, as formas $\mathrm{Vmc}, \mathrm{vm}, \mathrm{Vm}^{\text {ce }}, \mathrm{vm}^{\text {cês }} \mathrm{e} \mathrm{Vm}^{\text {ces }}$. Sabemos, até o momento, de um único dado com 'voce', sem acento, em carta de 10/1/1879.

A esse respeito, Cegalla (1977, p. 114) afirma que "Você (pl. vocês), usado no trato familiar e íntimo, é a redução de Vossa Mercê". Referindo-se a mais perdas em torno de 'você', Viaro (2011, p. 146) propõe o que se segue: "A possibilidade estrutural, a velocidade de fala e a alta frequência de uso são fatores que motivaram subtrações irregulares, como a já vista aférese ${ }^{6}$ de você $>$ *['vse] $>$ ['se], que se diferencia da aférese [o'se]<você'.

De volta à variável dependente, trazemos outros exemplos, agora somente com o verbo mandar, para dar a conhecer o fenômeno linguístico em estudo, que entendemos ser um fenômeno variável, já que contempla a existência de formas variantes. Em (13), abaixo, por exemplo, lemos 'me mande' mas não só. Há de se observar que o complemento verbal direto 'tudo que eu pesso' é realizado antes de 'me' e este, antes de 'mande', que é verbo com uso imperativo. O contexto sintático, então, se constrói com acusativo (tudo que eu pesso)+dativo (me, a mim)+verbo (mande). Diferentemente, em (14), os dois complementos verbais (acusativo e dativo) ocorrem depois do uso imperativo de mandar (mande): verbo (mande) + dativo (me) + acusativo (alem do que pesso $\mathrm{m}^{\mathrm{s}}$ uma arroba de assucar). Registramos, por fim, que também distinguimos a pessoa gramatical empregada em formas imperativas - mande (você), diferente de manda (tu); isto para avaliar se a pessoa do sujeito gramatical seria relevante para a opção pela próclise ou pela ênclise.

(13) Tudo que eu pesso me mande pelo $1^{\circ}$ Vapor ou o Villa Bella ou o Augusto ${ }^{7}$

(14) assim mande-me alem do que pesso $\mathrm{m}^{\mathrm{s}}$ uma arroba de assucar.

Sobre (13) e (14), podemos afirmar, enfim, que expressam variação no nível sintático da

${ }^{6}$ Aférese é nome dado à mudança fonética que resulta de uma transformação com supressão ou subtração de som inicial: acumen>gume. No nosso corpus, serve de exemplo o uso de 'ferro de gomar', em lugar de 'ferro de engomar': pedindo-me que eu mandasse buscar ahi um ferro de gomar para amulher aqui ganhar dinheiro (13/3/1879).

70 que lemos em (13) e em (14) está em longa carta de 13 de março de 1879. Esses dados são, pois, realizações de um mesmo informante, do sexo masculino, que escreve de Tabatinga (AM). Entenda-se $\mathrm{m}^{\mathrm{s}}$ como abreviatura de mais.

https://periodicos.unifap.br/index.php/letras

Macapá, v. 10, n. 1, $1^{\circ}$ sem., 2020 
língua, pois que dizer 'me mande' ou 'mande-me', nos contextos em estudo, não implica alteração no sentido do que se deseja expressar. Ali, então, os dois empregos (pré e pós verbal do clítico) correspondem ao que podemos chamar de variantes sintáticas, isto é, são formas intercambiáveis de mesmo sentido nos limites da frase de uma língua. Nesses casos, nos será possível dizer que uma construção equivale a outra quando pudermos "afiançar que temos duas construções sintáticas diferentes que expressam o mesmo sentido" (BELINE 2011, p. 124).

Sob tal orientação, nós procuramos descrever as escolhas de plano sintático que fazem os remetentes das cartas em estudo (estas, resultado de conhecimento que tem o falante sobre os usos que pertencem à sua própria língua). Para tal, desenhamos um ponto na linha do tempo do nosso português: de 1879 a 1889 - este, o período de tempo que até agora pudemos contemplar com o exame das cartas em estudo. E, desta maneira, ensejamos o desvelar de uma perspectiva de gramática - a descritiva, que "tem por objetivo registrar e descrever um sistema linguístico em todos os seus aspectos (e em todas as suas variedades), sem pretender recomendar um modelo exemplar" (BECHARA 2014, p.19).

Não se faz, portanto, estudo sincrônico ou diacrônico com preocupações normativas, ou juízos sobre certo e errado. O que se deseja, com a descrição, é revelar "a visão da língua em uso, com contínua competição das possibilidades de escolha” (NEVES 2014, p. 74).

Nesse sentido, as cartas manuscritas em questão poderão servir de subsídio para o conhecimento da língua em uso de então, "apesar das restrições necessariamente impostas na transferência do oral para o escrito" (MATTOS E SILVA 2006, p. 17). O que assumimos em relação aos nossos dados corresponde, por conseguinte, ao que a autora registra sobre dados escritos do período arcaico: "o texto escrito do período arcaico se aproxima, em geral, mais da fala do que os textos escritos posteriores à normativização gramatical” (MATTOS E SILVA 2006, p. 17).

\section{Detalhamento metodológico}

Em relação ao corpus que constituímos e de que tratamos neste artigo, somente relativo a cartas datadas de 1879 a 1889 , temos dificuldades em torno dos remetentes das cartas. O que deles sabemos é o sexo e conhecemos também a localidade de onde partem as cartas.

Ao nos deparamos com as dificuldades que se vão impondo, como as relativas à variável social sexo, por exemplo, dirigimos ainda maior atenção a tal fator, com o objetivo de determinar qual o seu peso na variação pesquisada, já que nossa hipótese de natureza sociolinguística entende a posição do clítico em relação ao verbo como uma alternância socialmente motivada. $\mathrm{Na}$ verdade, neste caso, importa sim fazer o registro de que as cartas eram escritas, em sua maioria, por homens.

No nosso corpus, sabemos somente de uma carta escrita por mulher; muito possivelmente porque poucas eram as mulheres que sabiam escrever à época (SILVA, 1974) e, por isso, eram representadas por seus maridos (ou pais, ou irmãos) que, provavelmente, tomavam decisões em torno das necessidades materiais da esposa (da filha, ou da irmã); como em carta de 10/01/1879: "Mande-me pelo $1^{\circ}$ portador ou vapor o seguinte -1 par de tamancos para mim e outro $\mathrm{p}^{\mathrm{a}}$ a Santa Anna conforme as medidas justas afim de sepoder andar por causa da lama".

Quando registramos, há de se pontuar, que só encontramos uma ocorrência de remetente de sexo feminino, não estamos desconsiderando o fator sexo no quantum ele possa ser ou não relevante para explicar a opção pela ênclise ou pela próclise, mas reunindo indícios de que a posição do clítico pronominal em relação ao verbo pode não ser determinada pela variável sexo.

Como não conhecemos também a formação escolar dos remetentes, não podemos descartar que tenham, alguns, recebido formação sistemática e regular na Europa, porque se sabe de estrangeiros vivendo, no Amazonas, no período de riqueza da extração de borracha. É português, por exemplo, o comendador Araújo.

Dentre os remetentes, pode haver, então, gente da terra, que escreve do lugar onde nasceu, e gente que veio para a região Amazônica em razão do trabalho ou da busca por riqueza com a 
extração da borracha. Em carta de 15 de janeiro de 1879, sabemos, por exemplo, da possível ida de cearenses para a região Amazônica: "Meo Amº isto aqui é bom, p" pr8 apraga e alama é que nos persegue, e estar um pouco despovoado; o Barão vai mandar $\mathrm{p}^{\mathrm{a}}$ aqui $\mathrm{m}^{\mathrm{s}}$ praças, e familias Cearenses pa oprogresso do lugar".

O fato é um só: ainda que nos faltem informações sobre algumas variáveis sociais, em se considerando o estágio de nossa pesquisa, avançamos com os estudos sobre a variável localidade, para examinar a sua relevância na adoção de uma ou de outra forma linguística entre os nossos dados. Não podemos, por isso, até que se tenham mais dados sociais dos remetentes das cartas em estudo (o que é objeto de parte de nossa equipe de pesquisadores), atestar sobre um português do Amazonas; daí dizermos que nossos estudos versam sobre um português registrado no Amazonas do período da borracha.

Iniciamos nossa análise recuperando aqueles dados que excluímos da contagem que daremos a conhecer. Não computamos, por exemplo, a ocorrência de 'lhe' em (15), por entendermos que expressa, juntamente com 'a voce', um duplo dativo, isto é, usar a ambos - lhe e a você - designa emprego redundante de um complemento verbal (no caso, indireto) de mesmo sentido, já que tanto um quanto outro dizem respeito a um mesmo conteúdo referencial, requerido pelo verbo enviar: envio a você, envio-lhe.

(15) $\underline{A}$ voce envio $\underline{\text { he }} \mathrm{m}^{\text {as }}$ saudades e creia que sou seu $A \mathrm{~m}^{\circ}$ Cincero

Não contamos as realizações de 'nos', como a ilustrada em $(16)^{9}$, por considerarmos que o pronome é ali, não um complemento do verbo, mas parte de sua pronominalização. No caso em (16), do verbo ir-se. Considerando-se a década de escritura das cartas que estamos levando em conta para fins deste artigo (1879 a 1889), o uso de ir-se e flexões fez-se muito frequente, o que acabou por reorientar nossa ideia inicial de que 'nos' correspondia a nós, a que simplesmente faltava o acento agudo.

(16) Nos vamos indo bem em novid ${ }^{e}$ graças a Deos

Como consequência, também não consideramos as realizações com os chamados verbos pronominais, tais como 'sujeitar-se a, ver-se obrigado a, achar-se em, servir-se de, responsabilizarse por'. Em exemplos dessa natureza sintática, tal como em (17), de 9/3/1879, os pronomes não exercem função acusativa ou dativa, ou seja, não são complementos verbais diretos ou indiretos.

(17) quero ter com antecedencia tudo $\mathrm{p}^{\mathrm{a}}$ não me sujeitar aos negociantes da qui.

Demos, também, outro tratamento aos verbos em locução; quer dizer, distinguimos os usos perifrásticos de verbos daqueles em que a forma simples é a principal. Não foram considerados, por isso, nos resultados de agora, os casos de auxiliares (ou verbos suporte) e mais o verbo principal, tais como: 'tenho me aguentado, me deve mandar, lhe mando pedir, a fim de lhe mandar pagar, tendo me faltado, não ter lhe remettido, me tinha escrito, não ter V. me escripto'.

\section{Resultados preliminares}

Quando dizemos, portanto, que os casos de próclise somam 57,31\% do total dos dados analisados e os de ênclise, 42,68\%, estamos nos referindo à posição que os pronomes assumem na relação com formas verbais simples, como exemplificado em (18), (19) e (20): o primeiro, de 10 de janeiro; o segundo, de 27 de março; o terceiro, de 11 de janeiro. Todos, de 1879.

(18) Pesso-lhe encarecidamente que me remetta algum Dinheiro.

(19) Remetta-me uma dusia debaralhos dos que custão $240 \mathrm{r}^{\mathrm{s}}$ cada um que é uma encommenda ${ }^{10}$.

(20) Manda me pelo1 ${ }^{\circ}$ vapor o que eu lhe pesso: a carne que seja boa, os tamancos que sejão tambem dos melhores

Ao dizermos, entretanto, que nossa pesquisa aponta tendência ao emprego da próclise - 'lhe

\footnotetext{
8 Entenda-se p $\mathrm{p}^{\mathrm{m}}$ como porém (conjunção de oposição, contraste) e pa como para (preposição).

9 Em (16), temos carta de 11 de janeiro de 1879. Entenda-se, ali, novide como novidade.

10 Em (19), encontramos a abreviatura da medida da moeda em uso à época: os réis.
} 
escrevo, me vendeo, me mande, me remetta', relativamente a dados dos anos compreendidos entre 1879 e 1889, estamos nos referindo somente a resultados com os empregos de 'me' e de 'The'. Sobre o 'me', temos 55 realizações de próclise e 47, de ênclise. Já em relação a 'lhe', temos 39 ocorrências de próclise e 23 de ênclise.

Nesse total, não estão as realizações de 'nos', porque, como foram somente 5 (cinco) as ocorrências deste pronome (uma única de ênclise, em 21, de 14/2/1881), optamos por reservar esse pequeno conjunto de dados para analisá-lo quando for maior o volume de cartas estudadas. Vemos esse uso de nós (ao que nos parece, inicialmente, pouco frequente) relacionado aos momentos em que o remetente insere as necessidades da família nos pedidos de compra. Daí ver-se, preponderantemente, ora o 'me', pronome que diz respeito ao remetente, aquele que formula o pedido de compra; ora o 'lhe', que se refere ao destinatário. Este, raramente tratado por te ou ti.

(21) disseram-nos que d'antes algumas cargas ião com frete pago até o lugar do distino, mas que hoje, por não haver tempo de calculal-o, vão com frete pago som ${ }^{e}$ até esse porto.

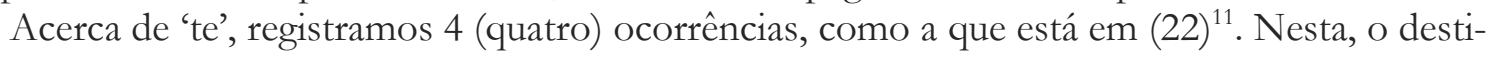
natário é identificado por formas que sugerem o tratamento dado à segunda pessoa gramatical 'tu': 'mandes' e 'te'. Também registramos um único dado, em (23), onde lemos o pronome 'ti', em lugar de 'te'; provavelmente refletindo a pronúncia de tal pronome à época. De todo modo, o contexto sintático de (23) requer uso dativo para o pronome: ou 'te' (que serve às expressões dativas e acusativas) ou 'a ti' (que serve, exclusivamente, ao uso dativo, porque complemento indireto da locução verbal 'quero dar').

(22) espero que me mandes pelo Vapor Obidos um par de tamancos para mim pela medida i na dessida do mesmo vapor te mando o Dinr ${ }^{\circ}$

(23) Quero ti dar um conselho e se aceitares seraes meos $\mathrm{Am}^{\circ}$ até morreres - não olhes $\mathrm{p}^{\mathrm{a}}$ essas mulheres amazonenses, e quando assim acontecer seja com cousa bõa e que tenha dinheiro e seja boa mulher e amorosa.

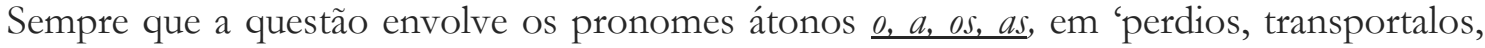
calculal-o, appromptat-o', por exemplo, atestamos criativas formas para dar conta dessa relação, tal como em (24), de 13/3/1879. Interessa-nos investigar como eles se comportam nos nossos dados, isto é, qual direção tomam - se enclítica, se proclítica, se o vazio. Sobre o tema, Nunes (1996) destaca a mudança da direcionalidade da cliticização: a língua, de enclítica, torna-se proclítica, posição a que não se adaptam 'o/a', donde o desaparecimento do clítico acusativo. Em razão, portanto, de poder estudar esse conjunto de dados sob a perspectiva de três movimentos de variação (a próclise, a ênclise, o vazio), decidimos excluí-los da contagem que ora apresentamos.

(24) mande-me sempre cousas boas, $\mathrm{p}^{\mathrm{s}}$ somos $\mathrm{am}^{\mathrm{os}} \mathrm{e}$ fregueses, e desejo ser bem servido e não quero desgostal-o em estar sempre lhe fasendo reclamações

Sobre (24), destacamos, especialmente, o uso de 'lo' em 'desgostal-o', indicando conhecimento em torno do emprego de clíticos acusativos na relação com verbos no infinitivo: des$\operatorname{gosta}(\mathrm{r})+(\mathrm{l})+\mathrm{o}$. Ainda a respeito desse conjunto de clíticos, registramos o dado em (25), onde está a única ocorrência, de até então, envolvendo a forma contraída de 'te + os', 'tos'; donde 'te' indica a quem (a ti) e 'os' substitui a quantia solicitada de 'dés mil reis'.

(25) Arranja-me dés mil reis agora, que no fim do mez tos restituo

Os dois únicos casos de mesóclise no corpus em estudo reportam-nos à carta de 1/1/1889: 'servir-se-ha e assignar-se-há'. Já podemos afirmar que os ambientes sintáticos com verbos no futuro do presente dão preferência à próclise, mesmo quando não há pronomes atrativos dela (da próclise): 'lhe despensará' e 'eu lhe serei', em cartinha de 3/2/1879, em (26), a seguir.

Acerca de 'eu the serei sumamente grato', destacamos o uso atrativo à próclise com a lexicalização do pronome sujeito 'eu’ e, também a julgarmos pela orientação normativa padrão dos nos-

${ }^{11} \mathrm{Em}$ (22), o registro é de 20 de abril de 1879; enquanto que o que está, em (23), é de 6 de abril do mesmo ano.

https://periodicos.unifap.br/index.php/letras

Macapá, v. 10, n. 1, $1^{\circ}$ sem., 2020 
sos tempos, não é 'lhe' um complemento de verbo mas de um nome, ou seja, do adjetivo 'grato'; ocorrência que escapa aos nossos critérios de contagem (selecionar, organizar e contar os casos de complementos verbais em função objeto).

(26) espero que oamigo lhe despensará seus boms serviços pelo que eu the serei summamente grato

Também sobre 'lhe', fomos percebendo, aos poucos, o emprego de 'a elle', escrito com 'll' e usado junto a verbos que exigem preposição. Notamos que, nesse contexto sintático, 'a elle' e 'lhe', em função de objeto indireto, parecem concorrer; se vão expressar uso variável, é o que devemos apreciar em pesquisa oportuna. Nos limites deste trabalho, constatamos que, nos verbos de transitividade indireta, ora lemos um, ora outro; às vezes, um e outro em um mesmo período, tal como provam (27) e (28), ambos de fevereiro de 1879.

(27) Estou certo que meo $\mathrm{Am}^{\circ}$ entregando tudo a elle e mostrando lhe apresente carta

(28) Rogo a V. Sa o favor de enviar-me a conta do restaurante q. lhe devo para meo governo

Fazemos notar, por fim, que tal escrita de 'elle' reporta-nos ao latim clássico, onde ille é pronome demonstrativo - aquele. A esse respeito, Mattos e Silva (2006, p. 109) demonstra que "a base -ill se especializou no português para cumprir a função de pronome pessoal de $3^{\mathrm{a}}$ pessoa, singular e plural (ele, eles; ela, elas)".

Ocupando-nos, uma vez mais, das descrições dos verbos de nosso corpus, desejamos dar destaque ao sistema de aviamento, que explicamos no início deste artigo. Nele, notamos o abundante uso do verbo 'mandar' em dois contextos principais: um, de verbo pleno, com objeto direto (e, às vezes, também indireto), como em (29) ${ }^{12}$; outro, como causativo, a favorecer o emprego de outro verbo no infinitivo, como em (30). Em relação a (29), temos 'manda-me tabaco bom e velho' e 'mande tambem garrafas de vinho'. Já (30) ilustra o uso causativo com 'mandei pedir'.

(29) Manda-me tabaco bom e velho por que aqui não há $\mathrm{m}^{\mathrm{s}}$ veja que eu não quero novo e sim velho e bom - este genero é de $1^{a}$ necessidade $\mathrm{p}^{\mathrm{a}}$ destrahir opensamento, $\mathrm{m}^{\text {de }}$ tbem umas garrafas de vinho de Lisboa

(30) Se não me mandares no $1^{\circ}$ Vapor o que mandei pedir me parece que morro de fome

Para tratar de um tipo de construção que chamam de transitiva (a causativa) ou construção bivalente, “em que o verdadeiro Agente ou 'executor' está ausente", Vilela e Koch (2001, p. 78) citam o exemplo 'O João construiu uma casa (= mandou construir)'. Nesse sentido, pode-se tomar (30): 'mandei pedir', ou 'mandei-te pedir' (padrão) - que se pode interpretar como 'eu mandei que tu pedisses', ou 'mandei tu pedir' (variedade do português brasileiro).

A esse tipo de construção Bagno (2014, p. 99) se refere, relacionando-a ao latim e, por conseguinte, ao acusativo com infinitivo. Ali, também, o objeto (acusativo) do verbo causativo é sujeito (nominativo) do infinitivo. O autor também relaciona a construção ao português, com o exemplo 'João mandou-me sair', em que 'me' é acusativo de 'mandou' mas sem deixar de ser nominativo de 'sair'. Tanto por isso ouvimos, em português do Brasil, a estrutura 'João mandou eu sair', em que se prefere usar o nominativo de sair (eu), em lugar do acusativo de mandou (me).

\section{Considerações finais}

O trabalho que aqui trouxemos resulta de nossa coordenação ao projeto de pesquisa sobre a História do português no Amazonas. A urgência e a necessidade de promover a organização de um conjunto de dados sobre o português registrado no Amazonas dos séculos XIX e XX encontram apoio no acervo J. G. Araújo, maior acervo do Museu Amazônico, órgão suplementar da Universidade Federal do Amazonas.

Além das cartas manuscritas, que constituem nosso corpus, fazem também parte do acervo J. G. Araújo outros documentos produzidos pela empresa de mesmo nome: Diário de Navegação, Escrituras de Seringais, contratos de trabalho, guias de embarque, coleção de letras de câmbio e

12 Em (29), está um trecho de carta de 11/1/1879. Em (30), de 9/2/1879.

https://periodicos.unifap.br/index.php/letras

Macapá, v. 10, n. 1, $1^{\circ}$ sem., 2020 
livros Diário e Razão. Um farto material, escrito, que, como dissemos antes, tem permitido que se conheça o modo de vida das pessoas que experimentaram, muito de perto, a extração e a comercialização do látex para a produção da borracha, em plena floresta amazônica e na passagem de dois séculos.

Lendo sobre o quotidiano daqueles tempos, nós nos apercebemos das lutas diárias de um lugar que contou importante fase da economia do Brasil, e o sabemos pelas palavras de quem aquela época viveu. Os fatos vão sendo contados - via sistema de aviamento - com o relato das histórias de pessoas que se moviam em 'vapor', assim como as cartas que elas escreviam. Com estas cartas, nós nos aproximamos da 'noticia de que todos gosão saude $\mathrm{p}^{\mathrm{r}}$ que nos vamos indo bem, sim $\mathrm{m}^{\text {ta }}$ praga e $\mathrm{m}^{\text {ta }}$ lama $\mathrm{p}^{\mathrm{r}}$ que tem chovido muito ${ }^{\text {,13 }}$, e passamos, também, a conhecer as emoções de uma gente resiliente: 'não tenho outro remedio senão hir suportando até qo ${ }^{\text {do }}$ Deos quizer, só tem bom o clima e os banhos a Santa Anna está satisfeita não obst tudo isto ${ }^{14}$.

Nossas descobertas, entretanto, vão mais além: enquanto tomamos conhecimento dos hábitos e costumes dos que viveram da floresta no período áureo da borracha, vamos nos familiarizando com 'os jeitos de dizer' dos remetentes das cartas em estudo. De olho no homem, na sua história pessoal e social, lançamo-nos a um estudo descritivo do português registrado nas correspondências escritas à mão, porque excluímos as datilografadas e as que trazem um modelo de preenchimento com os pedidos de compra. Interessa-nos quanto mais 'à vontade' parece estar o nosso remetente, como este que escreve em 10/1/1879: 'suponho que tão cedo não vou pa Manaos $\mathrm{p}^{\mathrm{r}}$ que tenho gostado do lugar: mande me o que lhe pesso Mande-me $\mathrm{m}^{\mathrm{s}}$ sebollas mas que venha bem agasalhadas'.

Assim procedendo, iniciamos a constituição do corpus da pesquisa - um conjunto de dados pouco estudado, tanto na perspectiva morfossintática, quanto na variacionista; esta última, tal como proposto por Labov (1972), de concepção e alcance, a um só tempo, sincrônicos e diacrônicos.

No trato das questões linguísticas, percebemos, ao longo da seleção dos dados, que temas afins vão se construindo - como, por exemplo, as realizações dos verbos lembrar e esquecer. Hoje, quando dizemos 'eu me lembro de' ou 'lembrei algo' - o mesmo se aplique em relação a 'esquecer' -, a perspectiva é agentiva, isto é, o sujeito gramatical põe-se como agente da ação expressa pelo verbo. Nem sempre foi assim, entretanto. E nossas cartas podem servir a estudos dessa natureza, como ilustrado em (31) e (32) ${ }^{15}$.

(31) Esquecia-me diserte que os seos phosphoros são os $\mathrm{m}^{\mathrm{s}}$ ordinarios que vi, os 3 pacotes que trouxe perdios $\mathrm{p}^{\mathrm{r}}$ que são na verd ${ }^{\mathrm{e}}$ ruins - com 1012 palitos fica a caixa sem serventia $\mathrm{p}^{\mathrm{a}}$ pegar fofo (32) Depois de ter fechado as $1^{\text {as }}$ cartas, lembrou-me $m^{\text {s }}$ depedir o que abaixo se segue

Lidando com temas relacionados a verbos, Melo (1971, p. 166) afirma que, "Dentre as formas nominais do verbo, não poucas foram as que esqueceram no latim vulgar". No português arcaico, a título de ilustração, podemos citar 'Nembrou-se da ameaça', que é o exemplo dado por Mattos e Silva (2006, p.158) para tratar de objeto direto reflexivo, correferente ao sujeito. Esta e outras mudanças de perspectiva, sobre o português do Brasil, podem nos ajudar a justificar a preferência pela próclise e consequente estabelecimento da posição proclítica como padrão do português brasileiro, principalmente quando o sujeito está anteposto ao verbo. Veja-se (33), de 27/3/1879. Depois, (34), de 13/3/1879.

(33) Olhe que a carne que $\mathrm{V}$. me enviou foi muito péssima

(34) e elle disse me tambem q. não tinha recebido

Não obstante o uso em (33), 'V. me enviou', deparamo-nos com (34), 'elle disse me', refletindo que há variação na relação que estamos estudando, a exemplo das pesquisas de Martins (2009) e de Pagotto (1992), que discutem o percurso diacrônico da posição dos clíticos.

Com o que pudemos trazer, portanto, a título da análise da posição que os clíticos (especial-

\footnotetext{
13 Carta de 11/1/1879.

14 Trecho de 15/1/1879.

15 O dado em (31) tem data de 15/1/1879. E o que está em (32), de 10/4/1879.
} 
mente 'me' e 'lhe') ocupam em relação a verbos, procuramos demonstrar que o nosso objeto de estudo é expressão de um fenômeno variável no nível sintático da língua portuguesa registrada nas cartas em estudo. A despeito do estágio inicial de nossos estudos sobre o tema em questão, porque grande é o volume de cartas à espera de análise, já nos foi possível indicar que a posição pré-verbal, ou o uso proclítico, apresenta-se como a posição preferida no nosso corpus, que por ora diz respeito ao período que compreende os anos de 1879 e

1889.

Com os nossos resultados, ainda que preliminares, constatamos a tendência à próclise entre os dados pesquisados; o que, linhas gerais, aponta o sentido da evolução da sintaxe dos clíticos na sua relação com formas verbais - o sentido da próclise - no decênio de registros, em português, no Amazonas dos tempos áureos da borracha. Uma preferência de uso que vemos assinalada no dizer de Galves (1996), quando trata do fenômeno da posição de clíticos como um dos aspectos mais fascinantes da emergência da gramática do português brasileiro: "sabemos que o PB moderno é fundamentalmente proclítico" (GALVES 1996, p. 393).

Por fim registramos que a pesquisa está em curso e que pretende, com as rodadas estatísticas, determinar os pesos relativos dos contextos preferenciais de uso de cada uma das formas variantes. Noutras palavras, se se prefere a próclise, importa diagnosticar quando e quais são as formas que lhe são atrativas - se as negativas, se os pronomes, se advérbios, por exemplo. Em análise, portanto e também, os seguintes grupos de fatores: a predicação do verbo, o tempo do verbo e a pessoa do verbo. O que se aplica, por conseguinte, aos valores de relevância das variáveis sociais.

A título de ilustração, citamos a variável localidade. Com ela pretendemos saber em que medida ocorre, nas localidades em estudo, a alternância que estamos estudando; para cotejar, por exemplo, com o que disse Madureira (2002, p. 112) sobre o uso/não uso da forma pronominal submeter-se a fatores dialetais, caracterizando-se como caso de variação linguística geográfica. Ou ainda, relativamente à variável faixa etária, se se pode afirmar o que constatou Duarte (1989, p. 27): "a ausência absoluta de clíticos na fala dos jovens".

\section{Referências}

BAGNO, Marcos A. Uma gramática propositiva. In: NEVES, M. H. de M.; CASSEB-GALVÃO, V. C. (Orgs.) Gramáticas contemporâneas do português: com a palavra, os autores. São Paulo: Parábola Editorial, 2014. p. 91-111.

BECHARA, Evanildo. Para quem se faz uma gramática? In: NEVES, M. H. de M.; CASSEBGALVÃO, V. C. (Orgs.) Gramáticas contemporâneas do português: com a palavra, os autores. São Paulo: Parábola Editorial, 2014. p. 19-30.

BELINE, Ronald. A variação linguística. In: FIORIN, J. L. (Org.) Introdução à Linguística. São Paulo: Contexto, 2011. p. 121-140.

CEGALlA, Domingos P. Novíssima Gramática da Língua Portuguesa. 16. Ed. São Paulo: Companhia Editora Nacional, 1977.

COELHO, Izete Lehmkuhl; GÖRSKI, Edair Maria; MAY, Guilherme Henrique; SOUZA, Christiane Maria Nunes de. Sociolinguística. Florianópolis: LLV/CCE/UFSC, 2010.

DUARTE, Maria Eugênia Lamoglia. Clítico Acusativo, Pronome Lexical e Categoria Vazia no Português do Brasil. In: TARALLO, Fernando (Org.). Fotografias Sociolinguísticas. Campinas, SP: Pontes: Editora da UNICAMP, 1989.

GALVES, Charlotte C. O enfraquecimento da concordância no português brasileiro. In: ROBERTS, Ian; KATO, Mary A. Português Brasileiro: uma viagem diacrônica. 2 ed., Campinas, SP: Editora da UNICAMP, 1996. p. 387-408.

LABOV, William. Sociolinguistic Patterns. Philadelphia: University of Pennsylvania Press, 1972. MADUREIRA, Evelyne Dogliani. Variação nas construções pronominais dos verbos psicológicos: uma decorrência de diferentes percursos históricos. In: COHEN, M.A.; RAMOS, J. Dialeto mineiro e outras falas. Belo Horizonte: FALE/UFMG, 2002. p. 109-130. 
MARTINS, M. Competição de gramáticas do português na escrita catarinense dos séculos 19 e 20. 2009. 326p; Tese (Doutorado em Linguística) - Universidade Federal de Santa Catarina, Florianópolis, 2009.

MATTOS E SILVA, Rosa Virgínia. O português arcaico: fonologia, morfologia e sintaxe. São Paulo: Contexto, 2006.

MELO, Gladstone C. de. Iniciação à Filologia e à Lingüística Portuguêsa. Rio de Janeiro: Livraria Acadêmica, 1971.

MELO, William Agel de. Dicionário Português Galego. Goiânia: Editora da Universidade Federal de Goiás, 1985.

MOLLICA, Maria Cecília. Fundamentação teórica: conceituação e delimitação. In: MOLLICA, M.; BRAGA, M. (Orgs). Introdução à Sociolinguística: o tratamento da variação. São Paulo: Contexto, 2003. p. 9-14.

NARO, Anthony Julius. Modelos quantitativos e tratamento estatístico. In: MOLLICA, M.; BRAGA, M. (Orgs). Introdução à Sociolinguística: o tratamento da variação. São Paulo: Contexto, 2003. p. 15-25.

NEVES, Maria Helena de M. Defino minha obra gramatical como... In: NEVES, M.H. de M.; CASSEB-GALVÃO, V. C. (Orgs.) Gramáticas contemporâneas do português: com a palavra, os autores. São Paulo: Parábola Editorial, 2014. p. 68-79.

NUNES, Jairo. Direção de cliticização, objeto nulo e pronome tônico na posição de objeto em português brasileiro. In: ROBERTS, I.; KATO, M. A (Orgs.). Português Brasileiro: uma viagem diacrônica. 2. ed. Campinas, SP: Editora da UNICAMP, 1996. p. 207-222.

PAGOTTO, E. A posição dos clíticos em português. Um estudo diacrônico. 1992. 157p.; Dissertação (Mestrado em Linguística) - Universidade Estadual de Campinas, Campinas. 1992.

PETTER, Margarida. Linguagem, língua, linguística. In: FIORIN, J. L. (Org.) Introdução à Linguística. São Paulo: Contexto, 2011. p. 11-24.

SILVA, Maria Beatriz Nizza da. Transmissão, conservação e fusão cultural no Rio de Janeiro (18081821). Revista de História (USP), v. XLVII, n. 97, p. 154-159, jan/mar 1974.

VILELA, Mário; KOCH, Ingedore V. Gramática da Língua Portuguesa. Porto, Portugal: Almedina, 2001.

VIARO, Mário Eduardo. Etimologia. São Paulo: Contexto, 2011.

WEINREICH, V.; LABOV, W.; HERZOG, M. Fundamentos empíricos para uma teoria da mudança linguística. São Paulo: Parábola, 2006 [1968]. 